Original Article

\title{
The effects of a client-centered leisure activity program on satisfaction, self-esteem, and depression in elderly residents of a long-term care facility
}

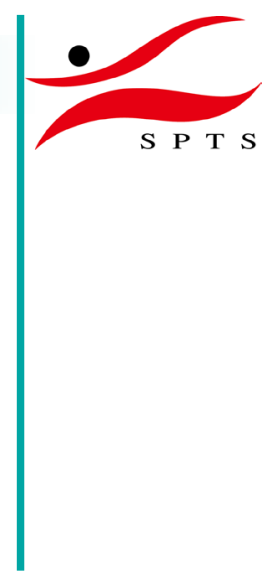

\author{
Ji-Yoon Jung, MSc, OT ${ }^{1)}$, So-Yeon PARK, PhD, OT ${ }^{2 *}$, Jin-Kyung KIM, PhD, OT ${ }^{3)}$ \\ 1) Education \& Development Team, Incheon Metropolitan Dementia Center, Republic of Korea \\ 2) Department of Occupational Therapy, Hanseo University: 46 Hanseo 1-ro, Haemi-myeon, \\ Seosan-si, Chungcheongnam-do, Republic of Korea \\ 3) Department of Occupational Therapy, Hanseo University, Republic of Korea
}

\begin{abstract}
Purpose] This study aimed to examine the effects of a client-centered leisure activity program on satisfaction, upper limb function, self-esteem, and depression in elderly residents of a long-term care facility. [Subjects and Methods] This study included 12 elderly subjects, aged 65 or older, residing in a nursing home. The subjects were divided into an experimental and a control group. Subjects in the control group received leisure activities already provided by the facility. The experimental group participated in a client-centered leisure activity program. The subjects conducted individual activities three times per week, 30 minutes per session. The group activity was conducted three times per week for eight weeks. Each subject's performance of and satisfaction with the leisure activity programs, upper limb function, self-esteem, and depression were measured before and after the intervention. [Results] After participating in a program, significant improvements were seen in both the Canadian Occupational Performance Measure and upper limb function in the experimental group. Also after the intervention, the subjects' self-esteem significantly increased and their depression significantly decreased. [Conclusion] A client-centered leisure activity program motivates elderly people residing in a long-term care facility and induces their voluntary participation. Such customized programs are therefore effective for enhancing physical and psychological functioning in this population.

Key words: Client-centered leisure activity program, Elderly people, Satisfaction
\end{abstract}

(This article was submitted Aug. 14, 2017, and was accepted Oct. 14, 2017)

\section{INTRODUCTION}

The elderly population in Korea currently accounts for $13 \%$ of the total population of 50 million, and this percentage is increasing ${ }^{1)}$. In addition, $89.2 \%$ of elderly Koreans suffer, on average, from 2.6 chronic diseases, thus supporting this population represents a social issue ${ }^{2}$. Korea introduced the long-term elderly care insurance system in 2008 in order to reduce the burden on elderly people ${ }^{3)}$. As a result, the number of recipients of long-term care services surged, and the rate of those applying for the service rapidly increased from $0.5 \%$ in 2008 to $4.2 \%$ in $2011^{4}$ ). This has increased the number of long-term care facilities and more than doubled the number of elderly occupants ${ }^{5}$. Nonetheless, the quality of services provided by these nursing facilities has suffered from a lack of evidenced-based policies ${ }^{6}$. For example, admission to these facilities is most often decided unilaterally by family members, who feel burdened by the support required. In addition, elderly people living in nursing facilities have less choice about how to utilize their time and less available leisure activities compared to

*Corresponding author. So-Yeon Park (E-mail: soyeon@hanseo.ac.kr)

C 2018 The Society of Physical Therapy Science. Published by IPEC Inc.

This is an open-access article distributed under the terms of the Creative Commons Attribution Non-Commercial No Derivatives (by-nc-nd) License. (CC-BY-NC-ND 4.0: https://creativecommons.org/licenses/by-nc-nd/4.0/) 
Table 1. General characteristics of the subjects

\begin{tabular}{|c|c|c|c|c|}
\hline \multicolumn{2}{|c|}{ Characteristics } & $\begin{array}{l}\text { Experimental group } \\
\qquad(\mathrm{n}=7)\end{array}$ & $\begin{array}{l}\text { Control group } \\
\qquad(\mathrm{n}=5)\end{array}$ & \multirow{2}{*}{$\begin{array}{l}\text { Total } \\
\text { n }(\%)\end{array}$} \\
\hline \multirow{3}{*}{ Gender } & & & & \\
\hline & Male & 4 & 3 & $7(58.3)$ \\
\hline & Female & 3 & 2 & $5(41.7)$ \\
\hline \multirow[t]{3}{*}{ Age(yrs) } & $65-75$ & 5 & 3 & $8(66.7)$ \\
\hline & $76-85$ & 2 & 0 & $2(16.7)$ \\
\hline & $>85$ & 0 & 2 & $2(16.7)$ \\
\hline \multirow[t]{4}{*}{ Education } & No grade & 1 & 1 & $2(16.7)$ \\
\hline & Elementary school & 2 & 1 & $3(25.0)$ \\
\hline & Middle school & 1 & 2 & $3(25.0)$ \\
\hline & High school & 3 & 1 & $4(33.3)$ \\
\hline \multirow{2}{*}{$\begin{array}{l}\text { Long-term care rates } \\
\text { for the elderly }\end{array}$} & 3 ranks & 4 & 4 & $8(66.7)$ \\
\hline & 4 ranks & 3 & 1 & $4(33.3)$ \\
\hline
\end{tabular}

Table 2. The experimental group's individual leisure activities

\begin{tabular}{cl}
\hline Subject & \multicolumn{1}{c}{ Leisure activity } \\
\hline A & Reading a history book, Writing a diary \\
B & Learning Chinese characters, Learning the Bible \\
C & Walking in the lobby, Reading a newspaper \\
D & Walking in the front of the district office, Learning Hangeul \\
E & Reading novels/essays, Walking in the lobby \\
F & Reading medical and science books, Writing \\
G & Playing yut, Playing janggi \\
\hline
\end{tabular}

those living within the community. As a result, elderly people often have difficulty adapting and develop emotional problems such as depression and anxiety ${ }^{2,7)}$. Research has previously examined the effects of insufficient leisure activities on elderly people in nursing facilities ${ }^{8}$. The leisure activities in these studies, however, were largely conducted in groups, failing to account for the individual's characteristics and preferred activities. To improve the life satisfaction of elderly people in long-term care facilities, leisure activities customized for each individual are necessary $\left.{ }^{9}, 10\right)$. Accordingly, this study provided a client-centered leisure activity program to elderly residents of a long-term care facility and examined its effect on satisfaction, self-esteem, depression and upper extremity strength and flexibility.

\section{SUBJECTS AND METHODS}

This study included 12 elderly residents of a nursing home (experimental group: 7, control group: 5) (Table 1). The selection criteria were: aged 65 or older residing in the nursing facility for at least six months prior to the start of the study, the ability to communicate, no severe physical disabilities such as an auditory or visual disability, and the ability to independently sit in a chair or a wheelchair for at least 30 minutes. All protocols were approved by the University of Hanseo. Before participation, the procedures, risks, and benefits were explained to the participants, who gave informed consent. Participant rights were protected according to the guidelines of the University of Hanseo. This study was conducted from September to November 2016. The control group performed existing leisure activities provided by the nursing facility and the experimental group conducted customized leisure activities (for individuals and groups) in addition to the existing leisure activities. Existing leisure activity programs provided to experimental group and control group were horticultural activity, folk song activity, art activity and were given once a week for 60 minutes each. The individual leisure activity program was composed of activities based on the participant's preferences determined from a face-to-face interview (Table 2) and was delivered by an occupational therapist three times per week for 30 minutes per session. The group leisure activity program was composed of a warm-up exercise for 10 minutes, an elastic band resistance exercise for 15 minutes, and a cool-down exercise for five minutes ${ }^{11}$. For group activities, the experimental group was divided into small groups consisting of three to five members. Each group conducted activities three times per week for eight weeks. The Senior Fitness Test Manual (lifting a dumbbell and holding the hands behind the back), the Rosenberg self-esteem scale (RSES), and the Korean version of the Beck Depression Inventory (K-BDI) were used in order to examine changes in the subjects' upper extremity function, selfesteem, and depression after the leisure activities. In addition, the Canadian Occupational Performance Measure (COPM) was used to examine participants' performance of and satisfaction with the leisure activity program ${ }^{12)}$. The pre-test for the experimental group was conducted during the first week of the experiment. Subjects underwent a total of 24 sessions of the customized leisure activities for eight weeks and the post-test was conducted during the 10th week. Likewise, the pre-test 
Table 3. Changes in upper limb muscle strength and flexibility between the experimental group and the control group (units=repetitions, $\mathrm{mm}$ )

\begin{tabular}{|c|c|c|c|c|c|c|}
\hline \multirow{4}{*}{$\begin{array}{l} \\
\text { Upper limb muscle } \\
\text { strength }\end{array}$} & \multirow{4}{*}{ Holding up a dumbbell (left) } & & Before & After & \multirow{2}{*}{ Z } & \multirow{2}{*}{$\mathrm{p}$} \\
\hline & & & \multicolumn{2}{|c|}{ Mean \pm SD } & & \\
\hline & & Experimental group & $16.14 \pm 8.45$ & $18.86 \pm 7.90$ & -2.38 & $0.017^{*}$ \\
\hline & & Control group & $7.2 \pm 5.85$ & $16.6 \pm 5.13$ & -0.97 & 0.334 \\
\hline & Holding up a dumbbell (right) & Experimental group & $21.29 \pm 2.69$ & $24.14 \pm 3.24$ & -2.39 & $0.017^{*}$ \\
\hline & & Control & $11.2 \pm 10.78$ & $10.2 \pm 9.76$ & -1.29 & 0.197 \\
\hline Upper limb flexibility & Holding the hands behind & Experimental group & $108.57 \pm 90.82$ & $75.71 \pm 87.91$ & -2.21 & $0.027^{*}$ \\
\hline & the back & Control group & $132 \pm 65.73$ & $146 \pm 54.13$ & -1.63 & 0.102 \\
\hline
\end{tabular}

$* p<0.05$, Experimental group $(n=7)$, Control group $(n=5)$.

Table 4. Changes in self-esteem and depression between the experimental group and the control group (unit=point)

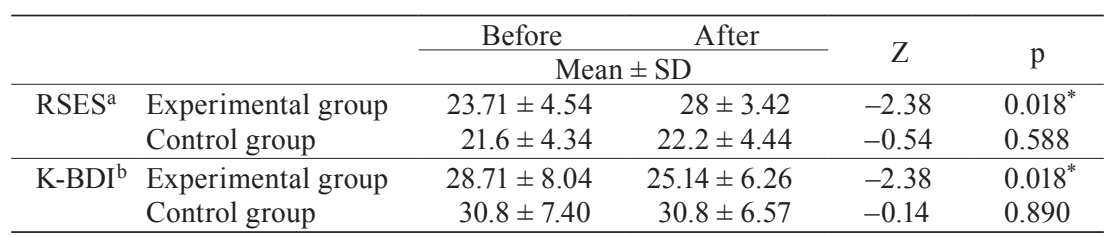

$* \mathrm{p}<0.05$, Experimental group $(\mathrm{n}=7)$, Control group $(\mathrm{n}=5)$, ${ }^{\mathrm{a}}$ Rosenberg self-esteem scale,

${ }^{\mathrm{b}}$ Korean version of the Beck Depression Inventory.

for the control group was conducted during the first week of the experiment, and these subjects participated in existing leisure activities provided by the long-term care facilities for eight weeks with the post-test conducted during the 10th week. Subjects in the control group were assured that once the effectiveness of the experiment was verified, the customized leisure activities would then be provided to them as well. The experimental results were statistically analyzed using the Statistical Package for the Social Sciences (SPSS) version 22.0 (IBM SPSS Statistics for Windows; IBM Corp., Armonk, NY, USA). Frequency analysis and descriptive statistics were utilized in order to examine the subjects' general characteristics. The Wilcoxon signed-rank test was employed to verify differences before and after the experiment in each group. The statistical significance level chosen was 0.05 .

\section{RESULTS}

The experimental group's COPM performance scores improved from an average of $1.71 \pm 0.49$ points to an average of $6.14 \pm 0.69$ points; the COPM-satisfaction scores also significantly improved from an average of $2.29 \pm 0.86$ points to an average of $6.43 \pm 1.21$ points $(\mathrm{p}<0.05$ ). The experimental group's upper limb muscle strength and flexibility significantly improved $(\mathrm{p}<0.05)$. The distance between the two hands when they held their hands behind their back decreased, which means increased flexibility $(\mathrm{p}<0.05)$ (Table 3$)$. The control group's upper limb muscle strength and flexibility did not significantly change after the intervention. The experimental group's self-esteem significantly increased after the intervention $(p<0.05)$. The experimental group's depression also significantly decreased after the intervention $(p<0.05)$. The control group's selfesteem and depression, however, did not significantly change after the intervention (Table 4).

\section{DISCUSSION}

This study was intended to examine the effects of a client-centered leisure activity program on satisfaction, upper limb function, self-esteem, and depression in elderly residents of a long-term care facility. The client-centered leisure activity program was comprised of individual and group activities. Performance of and satisfaction with individual activities in the experimental group both improved after the intervention. The elastic band exercise, a part of the group activity, effectively enhanced the experimental group's upper limb strength and flexibility ${ }^{13)}$. This result is consistent with previous research showing that elastic band exercise is effective for enhancing physical functioning in the eldery ${ }^{14)}$. The participants' selfesteem and depression also both significantly improved after the client-centered leisure activity program was implemented in the experimental group. This result is consistent with previous research demonstrating that elderly people who participated in leisure activities exhibited higher self-esteem and reduced depression ${ }^{2,15)}$. On the contrary, self-esteem and depression in the control group did not change. Thus, it is clear that individual programs based upon an individual's preferences are more effective for improving their participation in and satisfaction with leisure activities.

These results demonstrate that a program composed of activities customized to an individual resident can effectively 
improve their voluntary participation, which in turn decreases their depression, increases their self-esteem, and improves their physical functioning. The end result is that elderly residents have more satisfaction with the facility and a better quality of life.

One limitation of this study was that only activities applicable to long-term care facilities were used. In particular, dynamic activities with a high risk of fall, expensive activities, and activities provided by public facilities were excluded. In the future, prospective studies should seek to identify different strategies for improving elderly nursing facility residents' ability to adapt and their overall quality of life.

\section{REFERENCES}

1) Statistics Korea: Koreans statistical information service. http://kosis.kr/index.jsp

2) Park SY, Kim JK, Lee SA: The effects of a community-centered muscle strengthening exercise program using an elastic band on the physical abilities and quality of life of the rural elderly. J Phys Ther Sci, 2015, 27: 2061-2063. [Medline] [CrossRef]

3) Choi Y, Park S, Cho KH, et al.: A change in social activity affect cognitive function in middle-aged and older Koreans: analysis of a Korean longitudinal study on aging (2006-2012). Int J Geriatr Psychiatry, 2016, 31: 912-919. [Medline] [CrossRef]

4) Ministry of Health and Welfare: Welfare facilities for the elderly. http://kostat.go.kr/policy/quality/qt_dl/5/1/index.board?bmode=read\&aSeq=359004 (Accessed Jul. 5, 2016).

5) Choi YH, Kim NY: The effects of an exercise program using a resident volunteer as a lay health leader for elders' physical fitness, cognitive function, depression, and quality of life. J Korean Acad Community Health Nurs, 2013, 24: 346-357. [CrossRef]

6) Goh J, Hwang I, Oh H: The experiences of the newly admitted elderly residents in nursing home. J Korean Geriatr Soc, 2009 , 29: 477-488.

7) Choi Y, Park EC, Kim JH, et al.: A change in social activity and depression among Koreans aged 45 years and more: analysis of the Korean Longitudinal Study of Aging (2006-2010). Int Psychogeriatr, 2015, 27: 629-637. [Medline] [CrossRef]

8) Clark F, Jackson J, Carlson M, et al.: Effectiveness of a lifestyle intervention in promoting the well-being of independently living older people: results of the Well Elderly 2 Randomised Controlled Trial. J Epidemiol Community Health, 2012, 66: 782-790. [Medline] [CrossRef]

9) Kim KU, Kim SH, Oh HW: The effects of occupation-centered activity program on fall-related factors and quality of life in patients with dementia. J Phys Ther Sci, 2017, 29: 1188-1191. [Medline] [CrossRef]

10) Takemasa S, Nakagoshi R, Uesugi M, et al.: Factors that affect the quality of life of community-dwelling elderly women with musculoskeletal disorders. J Phys Ther Sci, 2015, 27: 3429-3431. [Medline] [CrossRef]

11) Thera-Band Academy: Resistance band \& tubing instruction manual, 5th ed. 2012, http://www.thera-bandacademy.com

12) Law M, Polatajko H, Pollock N, et al.: Pilot testing of the Canadian Occupational Performance Measure: clinical and measurement issues. Can J Occup Ther, 1994, 61: 191-197. [Medline] [CrossRef]

13) Ahn N, Kim K: Effects of an elastic band resistance exercise program on lower extremity muscle strength and gait ability in patients with Alzheimer's disease. J Phys Ther Sci, 2015, 27: 1953-1955. [Medline] [CrossRef]

14) Kim D: The effects of a combined physical activity, recreation, and art and craft program on ADL, cognition, and depression in the elderly. J Phys Ther Sci, 2017, 29: 744-747. [Medline] [CrossRef]

15) Kwak CJ, Kim YL, Lee SM: Effects of elastic-band resistance exercise on balance, mobility and gait function, flexibility and fall efficacy in elderly people. J Phys Ther Sci, 2016, 28: 3189-3196. [Medline] [CrossRef] 